\title{
Structural Adjustment Programme, Deforestation and Biodiversity Loss in Ghana *
}

\author{
JAMES K.A. BENHIN ${ }^{1}$ and EDWARD B. BARBIER ${ }^{2}$ \\ ${ }^{1}$ Centre for Environmental Economics and Policy in Africa (CEEPA), Educ. \& Law Building, Rooms \\ 3-32, University of Pretoria, Pretoria 0002, South Africa (E-mail: jbenhin@ postino.up.ac.za); \\ ${ }^{2}$ John S. Bugas Professor of Natural Resource and Environmental Economics, Department of \\ Economics and Finance, University of Wyoming, Laramie, WY 82971-3275, USA
}

Accepted 2 June 2003

\begin{abstract}
An empirical investigation is undertaken into the impact of the Structural Adjustment Programme (SAP) on forest and biodiversity loss in Ghana between the period 1965-1995. In the first part of the analysis, a four-equation recursive model, consisting of forest loss, cocoa land, maize land and timber production equations, is employed to examine the impact of the SAP on forest loss. The first equation is a function of the last three, and the last three are functions of mainly prices. Piecewise linear and switching regression approaches are used to distinguish between the influence of the post from the pre-adjustment impacts. These results together with a specie-forest area relationship are used to investigate the impact of the SAP on biodiversity loss. The overall results indicate that cocoa land expansion and timber production, but not maize land expansion, are the significant causes of forest loss in Ghana. However, the impact on forest loss in the postadjustment period was reduced. The rate of biodiversity loss also reduced in the post-adjustment period. Changes in relative output and input prices due to the SAP may have played a significant role in the reduced impact of agricultural and timber related deforestation and biodiversity loss in the post-adjustment period.
\end{abstract}

Key words: biodiversity loss, cocoa land, forest loss, Ghana, maize land, prices, structural adjustment, timber production

JEL classification: Q0, Q2, O1

\section{Introduction}

Recent studies on deforestation have analysed the relative importance of various economic activities including timber extraction and agriculture expansion in

\footnotetext{
^ This paper is part of a study undertaken in Ghana and Cameroon funded by the Center for International Forestry Research (CIFOR), the UK Darwin Initative, the Central Africa Regional Program for the Environment (CARPE) and the African Economic Research Consortium (AERC) for which we are very grateful. In particular, we acknowledge the support and helpful comments of Joane Burgess, David Kaimowitz, Jon Lovett, William Lyakurwa, Charles Perrings, Laurent Some and William Sunderlin. A version of this paper (Benhin and Barbier 1999a) was presented at the Ninth Annual Conference of the European Association of Environmental and Resource Economists (EAERE).
} 
causing tropical deforestation (see Brown and Pearce 1994; Kaimowitz and Angelsen 1997 for a review). Some studies have further looked into how the Structural Adjustment Programmes (SAP) through its impacts on timber extraction and agricultural land expansion, by the specific incentives of prices they influence, have affected the problem of deforestation on the tropics (see Deacon 1995; López 1997; Munasinghe 1996, 1999). However, very few of these studies have been undertaken in West Africa, where most of the countries have experienced high forest loss and have also embarked upon SAP reforms (FAO 1997; Benhin and Barbier 2001; Ehui and Hertel 1989; López 1997; Reed 1996; Sankhayan 1996). Moreover, only a limited number have extended their analysis to the SAP impact on biodiversity loss in the region.

However, these studies have generated from the international concern for the rate of tropical forest and more importantly the loss of biological diversity (hereafter referred to as biodiversity). ${ }^{1}$ The role of biodiversity has been well noted by Perrings (2000). The main value of biodiversity is thought to lie in the role of combinations of species supporting different ecosystem services: among others, watershed protection and the mitigation of floods and droughts, waste assimilation, microclimatic stabilization and the purification of air and water, the generation and renewal of soil and its fertility, the pollination of crops and other vegetation, the control of agricultural pests, the dispersal of seeds and the transport of nutrients.

It has been reported that, the highest rate of forest loss in Africa has occurred in West Africa with the most rapid forest clearance of between $1.3 \%$ and $1.5 \%$ occurring in countries including Ghana (FAO 1997; WRI 1994). This is one important indicator of habitat conversion and may have implications for biodiversity loss in Ghana (Barbier et al. 1995; Reid 1992).

This paper extends a previous study by Benhin and Barbier (2001) on the impacts of the Structural Adjustment Programme(SAP) on deforestation in Ghana to investigate the further implications for biodiversity loss, between the period 1965-1995. In their analysis, Benhin and Barbier identified food crops, such as maize and cash crops, such as cocoa production and timber extraction as the main proximate causes of forest loss in Ghana. The expected net benefits from these proximate causes of forest loss are in turn influenced by underlying factors, such as input and output prices. Macroeconomic policies, such as those undertaken under the SAP introduced in Ghana in April 1983, which include fiscal, monetary and trade and exchange rate policies (ISSER 1992), work through these underlying causes and other sector-specific policies to either mitigate or aggravate the influence of agriculture and timber extraction on deforestation. In addition given the area-species relationship (Reid 1992), the rate of forest loss induced by SAP policies may also have implications for biodiversity and its important functions. Empirically investigating the possible impacts of structural adjustment on biodiversity loss in Ghana is therefore the main focus of this paper.

In particular, three main hypotheses are examined in this paper. First we explore whether in recent decades, the expansion of land cultivated for cocoa and maize, 
and greater timber extraction, have been the proximate causes of forest loss in Ghana. The emphasis of land cultivation is on cocoa and maize because cocoa is the major export earner for the Ghanaian economy and maize is an important food crop in the country. Like cocoa, maize is also grown in the high forest zone of Ghana (Bateman et al. 1989). Second, since prices and other economic factors determining the expansion of these activities have been influenced by the Structural Adjustment policies in Ghana in the early 1980s, these policies may have also influenced forest loss significantly. Thirdly, as the fundamental specie-area relationship suggests that the number of species declines with forest habitat area, the same underlying factors determine biodiversity loss and so will the SAP policies which may have influenced these underlying causes.

In examining these hypotheses, the paper employs a four-equation recursive model, developed by Benhin and Barbier (2001), which consists of forest loss, cocoa land, maize land and timber production equations as a function of sectoral input and output prices and other factors, and a biodiversity loss equation. The hypothesised relationship between deforestation in Ghana and it's proximate and underlying causes is examined through estimating the recursive model for the 1965-1995 period. The possible influence of the structural adjustment programme on these relationships is analysed through employing piecewise linear and switching regression approaches to distinguish the influence of the post from the pre-adjustment period. To examine the third hypothesis, a species index is constructed for Ghana and together with the results from the recursive model is used to examine the impact of the SAP on biodiversity loss.

The rest of the paper is organised as follows: Below is a brief discussion of the role of timber and agricultural sectors on forest loss in Ghana and how the SAP has influenced this role. In section three, forest loss implications for biodiversity is discussed. The empirical model and biodiversity loss equation are presented in section four. The discussions of the estimates of the demand model and biodiversity loss equation are done in section five. A summary of the main results and some policy implications are found in the concluding section six.

\section{SAP and Forest Loss in Ghana}

Forest loss or deforestation, which in this paper refers to the actual yearly change in tropical forest in Ghana, has been so extensive and rapid that it is becoming increasingly difficult to get precise figures for the country's present forest cover and rates of deforestation. Repetto (1988) estimated the annual rate of deforestation during the period 1981-1985 to be 1.3\%. While the FAO (1997) has estimates of $1.5 \%$ for $1980-1990$ and $1.3 \%$ for $1990-1995$. The forest reserves now contain most of the country's remaining tropical moist forest, most of which even exist in isolated fragments. Forest loss in Ghana has been caused by the interaction of different factors: social, cultural, political and economic. The main proximate 
(direct) causes of forest loss, include fire, mining, quarrying, plantation strategy, but more importantly logging and farming (ITTO 1993).

Studies show that "salvage felling" which allowed unlimited felling of the largest or "over mature" trees and the "creaming" of high value species in the 1970s took a devastating toll on total forest cover and quality. This has been exacerbated by high levels of waste in timber extraction estimated to be as high as 50\% (Chachu 1989). Logging also makes the forest more susceptible to fire, and accessible to farmers. Moreover, commercially exploited areas have been repeatedly re-logged instead of being allowed to recover which leads to further forest loss and degradation (Hawthorne 1989; Martin 1991).

Low timber royalties and subsidized costs of extraction in the pre-adjustment period may have been an incentive for increased logging. In the Structural Adjustment period, macroeconomic policies leading to devalued exchange rates have increased the domestic returns from logging and therefore may have also increased the incentive for indiscriminate and destructive logging activities and their associated deforestation. This, however, may not necessarily be the case if the increased benefits from timber extraction leads to improved efficiency in timber extraction. Policies that raised the costs of logging, such as the imposition of higher royalties may also help reduce logging and their related deforestation (Richards 1995).

Agriculture is the largest and most important sector in Ghana (ISSER 1992, 1996) It employs about $60 \%$ of the population, with land and the forest as the main input in production. About 13.6 million hectares (ha), representing 57\% of the country's land area, are classified as suitable for agricultural purposes, of which about one-third was cultivated in 1990. Thus there is not yet a shortage of available land for agricultural production in Ghana (Ministry of Agriculture 1991).

The main problem is the opening up and conversion of marginal forested lands for cultivating some crops. Expansion of agricultural land is expected to proceed at a rate of $2.5 \%$ annually, mainly for the production of tree crops, such as cocoa, and food crops, such as maize (Ministry of Agriculture 1991). The productivity of land and labour in agriculture is very low due largely to the extensive use of traditional methods of cultivation such as slashing and burning the vegetation which also leads to widespread forest destruction.

Under the SAP, improved prices for cocoa and maize and improved credit facilities have been an incentive to expand production (ISSER 1992). The removal of subsidies on inputs like insecticides, and ammonium sulphate discourages the use of these inputs and therefore may have increased the use of land in agricultural production. These two policies point to a higher incentive to use more land, and therefore forest land, in production. It is however, possible that this may not be the case. This is because the increased crop prices, together with the availability of agricultural inputs and high yielding seeds may induce an increased substitution of these inputs for land (see Deacon 1995). The pressure on land and therefore forest land may fall. 


\section{Forest Depletion and Biodiversity Loss in Ghana}

The tropical high forest of Ghana as with other Guinea-congolean tropical forest is extremely heterogenous. Various surveys have shown high diversity of tree and animal species in Ghana's high forests. Between 680-2,100 plant species have been recorded, of which 420-680 grow to timber sizes and 126 of them in sufficient quantities for exploitation. Of these plant species, 23 of them are endemic (Hawthorne 1989).

The fauna of the forest zone also include more than 200 species of mammals, many of which are rare or endangered, including Bongo (Tragelaphus euryceros), Ogilby's duiker (Loxodonta africana cyclotis), and the Pygmy hippopotamus (Choeropsis liberiensis) (Mensah-Ntiamoa 1989). The rainforest zone also supports 74 species of bats, 37 species of small rodents, a variety of reptiles and over 200 species of birds (Sayer et al. 1992). In addition the forest performs key ecological functions as noted earlier.

However, given the rate of forest loss the diversity of the forest is at risk. In 1989, an inventory of more than 5,000 $\mathrm{km}^{2}$ of Ghana's tropical moist forest and 14 important species, found that the extraction rate of the traditional export timbers was far greater than their annual growth, giving them a limited "resource life" Afromosia (Pericopsi elata) was found to have been completely exhausted. IrokoOdum (Chlorophora/milicia excelsa), a species which has never been common in the country would also become exhausted within 10 years at current rates of exploitation but it was and continued to be exported in large volumes (Wong 1989).

Afromosia and iroko (Odum) are listed as either endangered or facing biological extinction in the West African region (Oldfield 1991). Further more, the IUCN's Threatened Plants Unit database lists ten timber species in Ghana that are of conservation concern (including Afromosia, and Talbotiella genti - the only truly endemic species in the country which is being endangered by plantation programmes). The increasing concern over the future conservation of Afromosia has prompted proposals for the specie to be listed under the Convention on International Trade in Endangered species of Wild Fauna and Flora (CITES) (Oldfield 1991).

Other studies on tree species on reserve harvest-profile, predict dramatic falls in future availability of groups of tree species termed Scarlet Red Star and Nannal Red Star species. Scarlet Red Star are species that are classified as under immediate threat of extinction. Narmal Red Star are species whose current rates of exploitation may present a significant danger of genetic erosion over 10 years, beginning in 1994. A third group, Pink-Red Star are type of species of trees significantly exploited but are not sufficiently under a threat at present.

According to estimations by an ITTO (1993) study, if the present levels of timber harvesting are maintained, over a period of 30 years, the annual harvest of Scarlet red and Normal Red Star species will fall by $26 \%$. And in the longer run, only very few species in these two groups will avoid commercial extinction. Moreover, total annual harvest on reserves is predicted to fall from about 405,000 cubic metres over a period of 50 years and later stabilize at about 268,000 cubic 
metres. This represents a clear pathway towards a degraded forest estate from which the industry can extract essentially only the lower value species (Wawa, Pink-red Star and "Other species"). This may imply high biodiyersity loss and negative ecological effects.

Off reserves harvest profiles also portrays that all the current most valuable species will be logged out in 20 years times. This will be caused by a total collapse in the harvest of Scarlet Red and Normal Red star species, which may be compensated, though to a limited degree, by a moderate rise in the harvest of some Pink-red star and Other species. Furthermore, over 20 years, the harvest of Wawa is also expected to fall drastically. After 20 years and beyond, total annual harvest will continue to fall slightly and stabilize around 557,000 cubic metres, however by then most of the important species (Scarlet Red and Normal Red star) would have been extinct.

The increasing loss of Ghana's forest and tree species have implications for the variety of fauna in the forest. The first reaction of many animals during and after logging operations and farming activities is, in the short term, to move away (Burgess 1971). This disrupts the complex interrelationships between plants and animals which will, in turn, greatly influence the mechanisms (and rates) of regeneration, reproduction and speciation in tropical forests. A variety of fauna are increasingly becoming rare in Ghana as a result of declining forest. Some of these fauna, already mentioned elsewhere, include the ogilby's duiker, forest elephants, bongo, giant forest hogs, several small antelopes, diverse primates (including chimpanzee and three species of colobus monkey) plus some species of bats and small rodents. Ghana also possesses several of West Africa's rarest birds, including a dozen species dependent on undisturbed forest (Burgess 1971).

Martin (1991) noted that one species of a primate, Red Colobus (Colobus badius), must be severely endangered because of the widespread of timber exploitation in West Africa which reduces its habitat. The IUCN (1988) also lists the species as endangered. One study on the Red Colobus confirmed that 43 per cent of the primate's diet comes from commercial timber species whilst another study observed that 25 percent of Ghanaian Red Colobus diet comes from five important species of timber trees - mahogany, iroko (Odum), sapele, utile and makore (all Scarlet red species). The Red Colobus is a leaf-eating specialist and relies very heavily on the canopy for movement and shelter and thus disappears from logged forests (Olsen and Curtin 1984; Struhsaker and Oates 1975).

The Diana Monkey (Cercopithecus diana), which Martin (1991) also considers to be endangered, feeds largely on tree species of which 20 per cent are commercially valuable, iroko and antiaris are particularly important (Olsen and Curtin 1984). Whilst the species does exist in secondary (disturbed) forests, it soon disappears once hunting pressure increases, a common problem in logged over areas (Martin 1991).

The very small and declining population of forest elephants (Loxondonta african cyclotis) in Ghana (Martin estimates that, in 1987, there were only 1,100 
elephants left in Ghana, and of these, at least half are likely to be savanna elephants) is considered to have very severe repercussions for the natural (and sparse) regeneration of a very important timber species, makore, (Tieghemella heckelii) and others of potential commercial interest. These are all trees with large seeds which are known to be dispersed only by sizeable mammals. The elephant is known to favour fruits from makore, as the seed passes through the animal's intestine unharmed and germinates very successfully in its dung (Martin 1991).

The overall consequence of elephant loss on the composition, richness and diversity of plant species in Ghana's forest may be substantial. In neighbouring Cote d'Ivoire, for example, 30 per cent of the seeds of tree species and 41 per cent of the seeds of tree individuals are dispersed by elephants (Alexandre 1978). Furthermore, the decline of natural elephants browsing tracks and pathways in primary forest is one reason cited for the now very small population of White-breasted Guineafowls (Agelastes meleagrides) which only exist in open floors beneath closed, canopy forest. Another reason cited for the reduction in the numbers of this bird, is logging (Kingdon 1990).

Other species which disperse fruits and seeds, and which are vulnerable to logging throughout West Africa, include, the dwarf hippo (Choeropsis lieriensis) and the giant forest hog (Hyclochoerus meinertzhagen) (Martin 1991). The absence of such feeding specialists will greatly influence the natural regeneration particularly for those species where seed, seedling or sapling mortality is high close to the parent tree (usually because of insect predation but also natural autotoxicity). In such instances, seed dispersal is vital. For example, saplings of idigo/framire (Tenninalia ivorensis) are unable to mature anywhere near a full-grown parent tree of the same species (Kingdon 1990)

The International Council for Bird Preservation (ICBP) and the IUCN observes that "the rate of forest destruction in Africa, west of the Dahomey gap is so severe that any bird species endemic to primary forest in this region must now be considered gravely at risk (ICBP/IUCN 1985). As well as the White-breasted Guineafowl, the Organizations list other Ghanaian bird species that fall into this category: Rufous fishing owl (Scotopelia ussher), Western wattled Cuckoo-shrike (Campephaga lobata), Yellow-throated olive Greenbul (Criniger Olivaceus) and White-necked Picathartes (Picarthartes gymnocepallus).

In addition, forest disturbance, either by excess timber exploitation and/or farming activities, can radically change the microclimate of the area. The rapid transformation to a more open, dry and sunlit environment has disruptive effects on wildlife and the natural regeneration (succession) of trees. Logging has been shown to cause rapid but aberrant, rank secondary growth overtopping usual colonizers of more natural gaps in the forest canopy. Soils become compacted and new seed banks and seedlings are destroyed under heavy logging equipment (Gartlan 1990). Nutrient loss is significantly higher on exposed soils than under a heavy canopy. Such events will further slow regeneration and influence species composition during succession. Moreover, according to World Bank (1989), soil erosion 
in Ghana under shifting cultivation (a phenomenon that so often follows logging) exceeds that for natural forest by a factor of twelve (i.e., depending on the slope and the types of soil, forest losses is approximately six tons or less per hectare a year compared to seventy tons or more in areas under this sort of cultivation). Water courses can be greatly affected through siltation.

Furthermore, the regulatory role of the forest in maintaining the atmosphere's carbon dioxide balance - the main greenhouse gas, is reduced and sometimes worsened, by deforestation. An estimated one-fifth of gases responsible for global warming are caused by the loss (particularly through burning) of tropical forests (Myers 1989). In a 1987 report, the ODA asserts that regional climatic change in Ghana is also occurring due to deforestation. It was observed that if logging and encroachment by farmers continue at the present rate the forest will disappear, causing climatic change, soil erosion and desertification. The desertification process has already begun in parts of the Upper and Northern regions.

In addition to the above, deforestation and biodiversity loss has an impact on the livelihood of local people. Non-timber forest products play important part in the everyday lives of many Ghanaians, particularly in the rural areas (Friends of the Earth 1992). Seventy-five per cent of the population regularly eat bushmeat, as well as a wide range of forest fruits. Plants are often used in construction or in the production of other goods (such as mats, baskets, furniture dyes; resins and gums). The rural population (almost without exception) relies on the use of traditional medicine, which is based on forest plants, as their main (and often only) source of health care. Approximately 2,000 plants are used locally for various ailments. A number of forest plants are also presently being exported from Ghana to be manufactured into medicine in Europe (Abbiw 1989). These benefits will be lost through excessive timber extraction and farming activities.

\section{The Model}

Benhin and Barbier (2001) employ an optimal control model of forest land allocation in Ghana to derive an empirical model for investigating the impact of the structural adjustment programme on deforestation. Essentially, maximising the net benefits from the forest land use for cocoa, maize, and timber production, the first order conditions are used to derive demand equations for optimal timber harvesting, cocoa land and maize land as functions of the price parameters in the model. A deforestation equation is also derived as a function of the change in the land uses and timber production, which is also by definition a function of the price parameters.

The empirical model from Benhin and Barbier (2001) which is adopted for this study is a four-equation recursive model consisting of the demand equations for timber extraction (1), cocoa land (2), maize land (3), and a forest loss equation (4)

$$
H_{t}=h\left(P_{t}^{h}, P_{t}^{c}, P_{t}^{m}, W_{t}^{h}, W_{t}^{c}, W_{t}^{m}\right)
$$




$$
\begin{aligned}
L_{t}^{c} & =c\left(P_{t}^{h}, P_{t}^{c}, P_{t}^{m}, W_{t}^{h}, W_{t}^{c}, W_{t}^{m}\right) \\
L_{t}^{m} & =m\left(P_{t}^{h}, P_{t}^{c}, P_{t}^{m}, W_{t}^{h}, W_{t}^{c}, W_{t}^{m}\right) \\
-\left(F_{t}-F_{t-1}\right) & =\left(L_{t}^{c}-L_{t-1}^{c}\right)+\left(L_{t}^{m}-L_{t-1}^{m}\right)+H_{t}=f\left(\ell_{t}^{c}, \ell_{t}^{m}, H_{t}\right)
\end{aligned}
$$

where;

$H_{t}$ is the demand for the stock of forest land for timber production;

$L_{t}^{i}=c$ and $m$, are the demand for the stock of forest land for cocoa and maize land respectively;

$F_{t}$ is the stock of total forest land (reserve and non-reserve);

$P_{t}^{i} ; i=h, c$ and $m$, are the output prices of timber, cocoa and maize respectively;

$W_{t}^{i} ; i=h, c$ and $m$, are the input prices of timber, cocoa and maize respectively;

$\ell_{t}^{i}=L_{t}^{i}-L_{t-1}^{i} ; i=c$ and $m$, are the changes in cocoa land and maize land respectively.

\subsection{BIODIVERSITY INDEX EQUATION}

This subsection attempts to derive a relationship between land use and biodiversity. The relationship is later used to estimate biodiversity indices in Ghana over the period 1965 and 1995, and to investigate the impact of the Structural Adjustment Programme on biodiversity loss,

Tropical deforestation is considered a significant factor in global biodiversity loss because the vast majority of terrestrial species occur in tropical moist forests. As a result, most predictions of global species extinction are usually projected on the basis of estimates of species richness in tropical forests, combined with actual and projected deforestation trends (Barbier et al. 1995). The extent of the relationship between tropical deforestation and biodiversity loss are, however, not very clear cut. Continuous efforts are being made to understand the extent of this relationship. Notable among the methods developed to estimate the relationship is the species-area curve, based on island biogeography theory, which states a relationship between the level of species and the area under forest.

Following Reid (1992) and others, a relationship between the number of species, $S_{F}$, and the area of forest is assumed as; ${ }^{2}$

$$
S_{F}(t)=F^{\alpha_{1}}(t)
$$

where:

$S_{F}(t)=$ a species index representing the number of species in a given forest area in time $t$. The greater the index the higher the level of biodiversity;

$\alpha_{1}=$ a parameter reflecting the "elasticity" or "responsiveness" of the species-forest area relationship.

It is further assumed that farms, especially cocoa farms, may contain some species of trees. This also follows the criticism by Lugo, Parrotta and Brown (1993) that the simple species-forest area relationship fails to take account of land use after forest clearing and assumes that land is biotically sterile after forest clearance. The 
import is that other land uses after forest clearance may contain some species. A species-farm land relationship, of cocoa land and maize land is therefore stated as follows;

$$
S_{L}(t)=\left(L^{c}(t)\right)^{\alpha_{2}}+\left(L^{m}(t)\right)^{\alpha_{3}}
$$

where:

$S_{L}(t)=$ a species index representing the number of species in a given farmland area in time $t$;

$\alpha_{2}=$ a parameter reflecting the strength of the species-cocoa land area relationship; $\alpha_{3}=$ a parameter reflecting the strength of the species-maize land area relationship.

Combining (5) and (6), the aggregate species-area relationship will be given as

$$
S(t)=S_{F}(t)+S_{L}(t)=F^{\alpha_{1}}(t)+\left(L^{c}(t)\right)^{\alpha_{2}}+\left(L^{m}(t)\right)^{\alpha_{3}}
$$

It is assume that $\alpha_{1}>\alpha_{2}>\alpha_{3}$. As the majority of trees have to be removed to make way for cocoa farming, one expects more species to be in a given forest area than on cocoa land $\left(\alpha_{1}>\alpha_{2}\right)$. However, because cocoa needs more shade than maize to grow and maize needs more cleared land, one also expects more species on cocoa farms than maize farms $\left(\alpha_{2}>\alpha_{3}\right)$.

From equation (7) the total level of biodiversity in each time period can be estimated by substituting the values of $F, L^{c}, L^{m}$. Given that $\alpha_{1}>\alpha_{2}>\alpha_{3}$ one would expect the total level of biodiversity in Ghana to decrease as the proportion of total land held as forest land falls over time. An increase in the proportion of farm land allocated to maize production would also cause $S(t)$ to decrease.

The problem is that the parameters $\alpha_{1}, \alpha_{2}$ and $\alpha_{3}$ for most tropical countries (including Ghana) are currently unknown. But since $\alpha_{1}$ had been estimated to be in the range, $0.16 \leq \alpha_{1} \leq 0.39$ (see Barbier et al. 1995), base on this, values for $\alpha_{2}, \alpha_{3}$ can be estimated on an assumed percentage of forest area that cocoa farmland and maize farmland may contain respectively. It is assumed that cocoa land may contain about $25 \%$ forest cover, while maize land may contain $5 \%$ forest cover. ${ }^{3}$ Given that the estimate for $\alpha_{1}$ implies a 100\% forest cover, the corresponding estimates for $\alpha_{2}$ and $\alpha_{3}$ are $0.04 \leq \alpha_{2} \leq 0.098$, and $0.008 \leq \alpha_{3} \leq 0.0195$. The estimated lower and upper boundary values of $\alpha_{1}, \alpha_{2}$ and $\alpha_{3}$, and the index of biodiversity levels, $S(t)$, are summarised in Table I, where $S_{1}(t)$ and $S_{u}(t)$ indicate the estimates for the lower and upper boundary levels respectively for each year's biodiversity.

Given equations (1), (2), (3), (4), and (7), it can be inferred that price changes that affect $L^{c}, L^{m}, H$, and $F$ will also affect species level, $S$ and therefore biodiversity loss. It also follows that policy changes, like the Structural Adjustment Programme, which influence prices will also influence biodiversity.

In the next section, we attempt to estimate the reduced form demand equations (1) to (3) and deforestation equation (4), and use them to explain the influence of the SAP on these relationships. We also attempt to estimate a time series of biodiversity index for Ghana, using equation (7), and given the estimates from (1) to (4), examine the impact of SAP on biodiversity between the period 1965-1995. 
Table I. Lower and upper boundaries of biodiversity indices in Ghana

\begin{tabular}{|c|c|c|}
\hline & Lower boundary $(l)$ & Upper boundary $(u)$ \\
\hline$\alpha_{1}$ & $\alpha_{1 l}=0.16$ & $\alpha_{1 u}=0.39$ \\
\hline$\alpha_{2}$ & $\alpha_{2 l}=0.04$ & $\alpha_{2 u}=0.098$ \\
\hline$\alpha_{3}$ & $\alpha_{3 l}=0.008$ & $\alpha_{3 u}=0.0195$ \\
\hline$S(t)$ & $S_{l}(t)=F^{\alpha_{1 l}}(t)+\left(L^{c}(t)\right)^{\alpha_{2 l}}+\left(L^{m}(t)\right)^{\alpha_{3 l}}$ & $S_{u}(t)=F^{\alpha_{1 u}}(t)+\left(L^{c}(t)\right)^{\alpha_{2 u}}+\left(L^{c}(t)\right)^{\alpha_{2 u}}$ \\
\hline
\end{tabular}

\section{Estimation Procedure and Discussion of Empirical Analysis}

The hypothesized relationship between deforestation in Ghana and it's proximate and underlying causes is examined through estimating for the 1965-1995 period a modified form of equations (1)-(4). We assumed that these relationships are also affected by income (per capita GDP, $Y_{p}$ ) and the population (population density, popd). ${ }^{4}$ The possible influence of structural adjustment on these relationships is analysed through employing a piecewise linear (PW) and switching (SW) regression approaches to distinguish the influences of the post from the preadjustment period. ${ }^{5}$ The possible influence of SAP on biodiversity is also examined by constructing a specie index for Ghana based on estimates from equation (7) and using the various land uses over the period. This index together with the estimated demand for forest land equations (1)-(4) are then used to examine the impact of the SAP on biodiversity loss. Secondary data, collected mainly, from the Food and Agriculture Organization (FAO), the Ministry of Agriculture and the Forestry Department of Ghana were used in the estimation (see Table II and Appendix 1). ${ }^{6}$

The modified equations to be estimated for timber production, cocoa land, maize land and forest loss respectively are stated as follows:

$$
\begin{aligned}
H_{t}= & \beta_{01}+\beta_{11} P_{t}^{h}+\beta_{21} P_{t}^{c}+\beta_{31} P_{t-1}^{m}+\beta_{41} W_{t}^{h}+\beta_{51} W_{t}^{c} \\
& +\beta_{61} W_{t}^{m}+\beta_{71} Y p_{t}+\beta_{81} \text { popd }_{t}+\mu_{1 t} \\
L_{t}^{c}= & \beta_{02}+\beta_{12} P_{t}^{h}+\beta_{22} P_{t}^{c}+\beta_{32} P_{t-1}^{m}+\beta_{42} W_{t}^{h}+\beta_{52} W_{t}^{c} \\
& +\beta_{62} W_{t}^{m}+\beta_{72} Y p_{t}+\beta_{82} \text { popd }_{t}+\mu_{2 t} \\
L_{t}^{m}= & \beta_{03}+\beta_{13} P_{t}^{h}+\beta_{23} P_{t}^{c}+\beta_{33} P_{t-1}^{m}+\beta_{43} W_{t}^{h}+\beta_{53} W_{t}^{c} \\
& +\beta_{63} W_{t}^{m}+\beta_{73} Y p_{t}+\beta_{83} \text { popd }_{t}+\mu_{3 t} \\
-\left(F_{t}-F_{t-1}\right)= & \beta_{04}+\beta_{14}\left(L_{t}^{c}-L_{t-1}^{c}\right)+\beta_{24}\left(L_{t}^{m}-L_{t-1}^{m}\right) \\
& +\beta_{34} H_{t}+\mu_{4 t}
\end{aligned}
$$

Table II provides definition of the variables used in (8)-(11). All price variables and GDP per capita are in constant 1990 values. Current years' output prices are used for timber and cocoa, because timber prices are based on current years' contracted price and, cocoa prices are government determined. However, for maize, farmers do not know how much they would receive for their produce, since the 
Table II. Definition and sources of data for the analysis

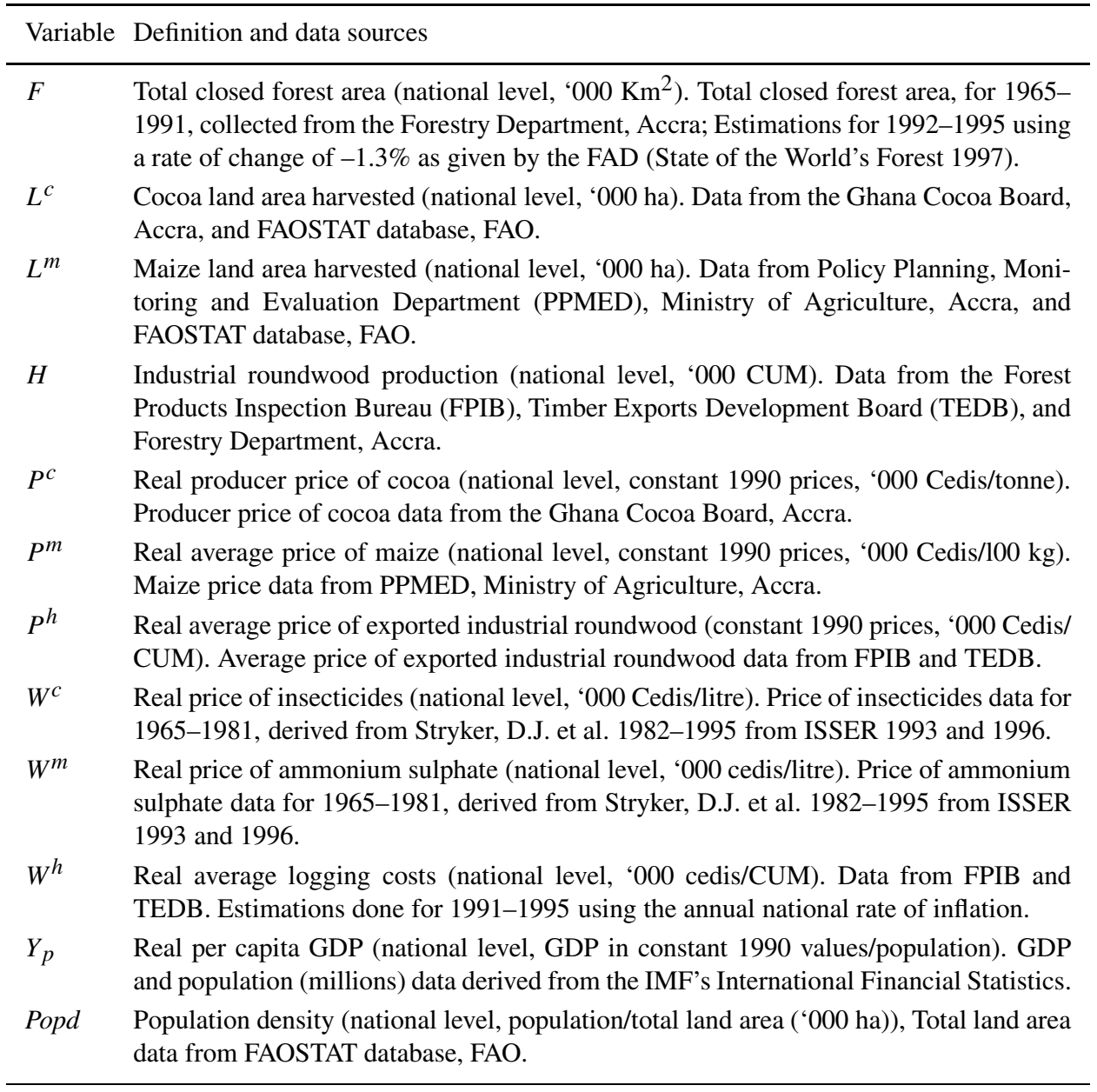

Note: The consumer price index (CPI) for 1990 was used to estimate the real prices.

eventual price depends on how much is produced in the current year. Therefore, decisions on maize land in the current year depend more on what prices were in the previous year.

Given that all the explanatory variables in equations (8)-(11) are exogenous, the model is recursive, and so Ordinary Least Squares (OLS) is a reasonable procedure for the time series analysis. ${ }^{7}$ A Cochrane-Orcutt iterative approach was adopted for the estimation to correct for autocorrelation where it was detected. The first step in the estimation procedure was to determine whether there is any significant difference in the functional forms (linear and $\log -\log$ ) of the estimated equations. This was done by the use of the Mackinon, White and Davidson (MWD) test (Gujarati 1995). 
The next step was to determine whether the piecewise linear (PW) or the switching (SW) regression approaches allowing for the influence of structural adjustment is preferred to the continuous regression of the entire 1965-1995 period. First, the data were separated into pre-adjustment (1965-1982) and postadjustment (1983-1995) periods. Estimations were done for the two separate periods and a Chow test was applied to determine whether the two regressions are significantly different. Where the Chow test showed a significant difference, the appropriate structural adjustment dummy variables ( $D P$ for the $\mathrm{PW}$ and $D S$ for the SW) were included in the model for the estimation of the piecewise linear or the switching regressions.

The final step was to determine whether the piecewise linear or the switching regression is the best approach for capturing any influence of the structural adjustment "break" in the estimated relationships. This was done in three ways: First, by comparing the adjusted R-squares of the two types regressions; second, by comparing the level of significance of the coefficients of the dummy explanatory variables in the respective regressions; and third, by comparing the joint significance of their dummy explanatory variables using the F-test (Gujarati 1995).

Implementing the above procedures led to the following results for the overall model. The MWD tests showed that, the linear functional form was preferred to the $\log -\log$ functional form in all the four equations. The piecewise linear regression allowing for the influence of the SAP was preferred in the demand for land for cocoa production, and for the forest loss equations, while the switching regression was preferred in the equation for maize land. In the timber equation, however, the linear estimation without the structural change influence was preferred. In all the estimations, except for the forest loss equation, the Cochrane-Orcutt iterative procedure was used to correct for the presence of autocorrelation. ${ }^{8}$ The following discusses each of the estimated equations, starting with forest loss (11), then cocoa land (9), maize land (10) and finally timber production (8).

\subsection{FOREST LOSS RESULTS}

A Chow test performed on equation (11) confirmed a significant difference between the pre and post adjustment period. The estimated results are presented in Table III. ${ }^{9}$ In the pre-adjustment period there was a positive relationship between the change in harvested cocoa land expansion and forest loss. A 1000 ha increase in change in cocoa land led to about $0.95 \mathrm{~km}^{2}$ increase in closed forest area loss. Total timber production also led to an increase in forest loss. A 1000 cum increase in total industrial roundwood production led to about $0.2 \mathrm{~km}^{2}$ increases in closed forest area loss (Table III), The hypothesis that cocoa land expansion and timber production are important proximate factors in forest loss in Ghana is therefore supported by the model in the pre-adjustment period.

There is a significant difference in the impacts of forest loss due to a change in cocoa land in the pre and post-adjustment period. Table III shows that in the 
Table III. Ordinary least squares estimation of the forest loss equation for Ghana Dependent variable $=-\left(F_{t}-F_{t-l}\right)$ : change in total closed forest area in '000 sq km

Estimated piecewise linear regression for equation (11):

$$
\begin{aligned}
-\left(F_{t}-F_{t-l}\right)= & \beta_{04}+\beta_{14}\left(L_{t}^{c}-L_{t-1}^{c}\right)+\beta_{24} H_{t}+\beta_{34} D 1 \\
& +\beta_{44}\left(\left(L_{t}^{c *}-L_{t-1}^{c *}\right) D P+\beta_{54}\left(H_{t}^{*}\right) D P+\mu_{4 t}\right.
\end{aligned}
$$

where:

$L_{t}^{c *}-L_{t-1}^{c *}=\left(L_{t}^{c}-L_{t-1}^{c}\right)-\left(L_{t_{0}}^{c}-L_{t_{0}-1}^{c}\right) ; t_{0}=1983$

$H_{t}^{*}=H_{t}-H_{t_{0}} ; t_{0}=1983$

$D l=$ dummy for 1968

\begin{tabular}{|c|c|c|c|c|c|c|c|c|}
\hline \multirow[t]{2}{*}{ Variable } & \multicolumn{3}{|c|}{ Estimated results } & \multicolumn{2}{|c|}{ Pre-adjustment } & \multicolumn{3}{|c|}{ Post-adjustment } \\
\hline & \multicolumn{2}{|c|}{ coefficients } & \multirow{2}{*}{$\begin{array}{c}\text { t-values } \\
0.275\end{array}$} & $\begin{array}{c}\text { marginal } \\
\text { values }\end{array}$ & \multirow[t]{2}{*}{$\begin{array}{l}\text { Est. } \\
\text { elast. }{ }^{1}\end{array}$} & \multicolumn{2}{|c|}{$\begin{array}{c}\text { marginal } \\
\text { values }\end{array}$} & \multirow[t]{2}{*}{$\begin{array}{l}\text { Est. } \\
\text { elast. }^{1}\end{array}$} \\
\hline Constant & $\beta_{04}$ & 53.75 & & $\beta_{04} \quad 53.75$ & & $\beta_{04}$ & 53.75 & \\
\hline$\left(L_{t}^{c}-L_{t-1}^{c}\right)$ & $\beta_{14}$ & $0.95^{* *}$ & 2.231 & 0.95 & -0.157 & $\beta_{14}+\beta_{44}$ & -0.35 & -0.191 \\
\hline$H_{t}$ & $\beta_{24}$ & $0.21^{*}$ & 1.783 & 0.21 & 1.069 & $\beta_{24}+\beta_{54}$ & -0.12 & -2.39 \\
\hline D1 & $\beta_{34}$ & $-606.02^{* *}$ & -2.368 & $\beta_{34}-606$ & & $\beta_{34}$ & -606 & \\
\hline$\left(L_{t}^{c *}-L_{t-1}^{c *}\right) \mathrm{DP}$ & $\beta_{44}$ & $-1.29^{*}$ & -1.936 & & & & & \\
\hline$\left(H_{t}^{*}\right) \mathrm{DP}$ & $\beta_{54}$ & -0.33 & -1.667 & & & & & \\
\hline R-square $=0.493$ & & $\mathrm{~F}=4.671$ & DY & statistic $=2$ & & No. of obse & rvation & $s=30$ \\
\hline
\end{tabular}

$D P=$ dummy for the structural adjustment period in Ghana; $D P= \begin{cases}1 & \text { if } t>\text { year } 1983 \\ 0 & \text { if } t \leq \text { year } 1983\end{cases}$

Note: (1) The dependent variable is positive, therefore a positive coefficient means increasing levels of the explanatory variable leads to increasing levels of forest loss whereas a negative coefficient means increasing levels of the explanatory variable leads to falling levels of forest loss. (2) See endnote 9.

${ }^{1}$ Elasticities were calculated by using the means in the respective periods.

${ }^{* * *}$ Coefficients statistically significant at $1 \%$ level.

** Coefficients statistically significant at $5 \%$ level.

${ }^{*}$ Coefficients statistically significant at $10 \%$ level.

post-adjustment period, cocoa land expansion reduces the rate of forest loss. A 1000 ha increase in harvested cocoa land expansion leads to a reduction in forest loss by $0.35 \mathrm{~km}^{2}$. The elasticity shows that a one per cent increase in cocoa land expansion leads to the rate of forest loss or the rate of deforestation falling by about $0.2 \%$. There is however, not much significant difference between the impact of industrial roundwood production in the pre and post-adjustment period. Even though the estimated marginal value is negative, with the elasticity portraying that a one per cent increase in industrial roundwood leads to a $2.4 \%$ fall in the rate forest loss or the rate of deforestation, the post-adjustment dummy coefficient $\left(\beta_{54}\right)$ is not very significant. It can therefore be stated that timber production still has a negative impact on the forest in Ghana. To some extent, however, this impact has reduced 
although the coefficient of the post-adjustment timber production dummy is not fully significant.

One factor explaining this latter regression result is that industrial roundwood production might have captured most of the effects of changes in both cocoa and maize land on deforestation. Amelung and Diehl (1992) have noted that more than $70 \%$ of the primary forest areas brought under cultivation are first degraded by commercial logging and according to the FAO, deforestation rates due to agricultural conversion are eight times greater in logged-over forests than undisturbed forests (Sun 1995). Barbier (1994) also reports that in many African countries, around half of the area that is initially logged is subsequently deforested, while there is little if any deforestation of previously unlogged forest lands.

Another explanation is that cocoa and especially maize farmers may be shifting production from existing land to either new forest land or fallow land, or to old cocoa farms in the case of maize. Thus when the total harvested area of cocoa or maize land is estimated, it might appear to be constant, but the proportion of the total harvested land from forest area, may be higher or lower. The fact is that it is difficult to estimate how much of the newly harvested area in each period is from converted forest land. It follows also that even though the maize land variable was not important in the estimated regression, given the reasons stated above, there is a strong believe that maize and other food crops are important determinants of forest loss in tropical countries.

To summarize, the regression results do not support the hypothesis that expansion in maize land is a significant proximate cause of forest loss, either in the pre or post-adjustment period in Ghana. Cocoa land expansion was a significant proximate cause in the pre but not in the post-adjustment period. However, industrial roundwood production is a significant proximate factor in both periods, though less so in the post-adjustment period. A tentative inference from the above results is that if the "right" incentives that influence these commodities such as output and input prices can be found, their role in forest loss in tropical countries could be reduced. The next step in the analysis is to look at how output and input prices in the agricultural and forestry sectors during the pre and post-adjustment periods may have influenced these proximate causes of forest loss in Ghana.

\subsection{HARVESTED COCOA LAND}

A Chow test performed on equation (9) confirmed a significant difference between the pre and post-adjustment period. The estimated piecewise linear regression results for cocoa land and the computed marginal values and elasticities are presented in Table IV. Other price Variables' $P^{m}, P^{h}, W^{m}, W^{h}$, and the population density ( $p o p d$ ), were not significant and therefore were dropped in the piecewise regression. The inference is that, from the point of view of the cocoa farmer in Ghana, maize is not an alternative crop in land use decision making, and thus maize output and input prices $\left(P^{m}\right.$ and $\left.W^{m}\right)$ are not relevant to the cocoa farmer. 
The insignificance of population density variable (papd) suggests that population changes have very little or no impact on cocoa land expansion in Ghana. Input prices of cocoa $\left(W^{c}\right)$, per capita GDP $\left(Y_{p}\right)$ and the dummy for the bush fires effect in 1983-1986 (D2) appear to be the most important variables determining the rate of cocoa land expansion between 1965-1995.

In the pre-adjustment period, the relationship between the price of cocoa and cocoa land expansion is negative but not significant (Table IV). The explanation for this result is the low fixed producer prices of cash crops in that period, which had very little influence on cocoa land expansion. Cocoa land expansion in Ghana in that period was more influenced by factors other than the producer price of cocoa. The influence of the producer price of cocoa on forest loss in the pre-adjustment period was therefore very minimal.

In the post-adjustment period, the relationship between the price of cocoa and cocoa land is still negative but also not significant. This may be attributable to the rate of devaluation which enabled the country to consistently increase the producer price of cocoa in the post-adjustment period (Benhin and Barbier 1999b). The negative relationship between price of cocoa and cocoa land may therefore indicate that with the consistent increases in the producer price of cocoa during the postadjustment period, farmers with expectations of further, higher prices may have had the incentive to rehabilitate and invest in existing farms rather than open up new lands. The conclusion is that although higher prices in the post-adjustment period may have helped reduce the impact of the producer price of cocoa on cocoa land expansion the prices are still not high enough to significantly influence a reduced cocoa land expansion. As noted by Benhin and Barbier (1999b), the real prices of cocoa are still below the 1970's prices. Factors, other than the producer prices of cocoa may have contributed more to the reduction in the rate of cocoa land expansion.

The regression results show a significant positive relation between the price of insecticides $\left(W^{c}\right)$ and the demand for cocoa land in the pre-adjustment period in Ghana (Table IV). This means that in that period, insecticides were a substitute to cocoa land in cocoa production. A one per cent increase in the price of insecticides led to about $0.11 \%$ increase in cocoa land. Although in the pre-adjustment era there were high subsidies on insecticides, given the low producer price of cocoa, many cocoa farmers could not afford to buy the input. Moreover, insecticides were very scarce because of the lack of foreign exchange to import them. Therefore, the alternative to using more insecticides to increase production was to rely on new opened lands for production. The unavailability of insecticides, in spite of the subsidies, increased the pressures on the forest due to cocoa land expansion in Ghana in the pre-adjustment period.

The impact of the price of insecticides on cocoa land changed significantly in the post-adjustment period in Ghana (Table IV). Insecticides and cocoa land now appear to be complements in cocoa production. A one per cent increase in the price of insecticides leads to a $0.024 \%$ fall in cocoa land. Given the increasing 
Table IV. Ordinary Least squares estimation of the Cocoa land equation for Ghana Dependent variable $=\left(L^{c}\right)$ (harvested cocoa land in '000 ha)

Estimated piecewise linear regression for equation (9):

$$
\begin{aligned}
L^{c}=\beta_{02}+ & \beta_{12} P^{c}+\beta_{22} W^{c}+\beta_{32} Y_{p}+\beta_{42} D 2 \\
& +\beta_{52}\left(P^{c *}\right) D P+\beta_{62}\left(W^{c *}\right) D P+\mu_{2 t}
\end{aligned}
$$

where:

$D 2=$ dummy for year 1983-1986; D2 $=\left\{\begin{array}{l}1 \text { for } 1983 \leq \text { year } \geq 1986 \\ 0 \text { for all other years }\end{array}\right.$

$P^{c *}=P_{t}^{c}-P_{t_{0}}^{c} ; t_{0}=1983$, onset of SAP in Ghana;

$W^{c *}=W_{t}^{c}-W_{t_{0}}^{c} ; t_{0}=1983$, onset of SAP in Ghana;

\begin{tabular}{|c|c|c|c|c|c|c|c|c|c|}
\hline \multirow{3}{*}{$\begin{array}{l}\text { Variables } \\
\text { Constant }\end{array}$} & \multicolumn{3}{|c|}{ Estimated results } & \multicolumn{3}{|c|}{ Pre-adjustment } & \multicolumn{3}{|c|}{ Post-adjustment } \\
\hline & \multicolumn{2}{|c|}{ coefficients } & \multirow{2}{*}{$\begin{array}{c}\text { t-values } \\
0.272\end{array}$} & \multicolumn{2}{|c|}{$\begin{array}{c}\text { marginal } \\
\text { values }\end{array}$} & \multirow[t]{2}{*}{$\begin{array}{l}\text { Est. } \\
\text { elast. }{ }^{1}\end{array}$} & \multicolumn{2}{|c|}{$\begin{array}{c}\text { marginal } \\
\text { values }\end{array}$} & \multirow[t]{2}{*}{$\begin{array}{l}\text { Est. } \\
\text { elast. }{ }^{1}\end{array}$} \\
\hline & $\beta_{02}$ & 76.78 & & $\beta_{02}$ & 76.78 & & $\beta_{02}$ & 76.78 & \\
\hline$P^{c}$ & $\beta_{12}$ & -5.76 & -1.17 & $\beta_{12}$ & -5.76 & -0.11 & $\beta_{12}+\beta_{52}$ & -2.54 & -0.059 \\
\hline$W^{c}$ & $\beta_{22}$ & $9.12^{* * *}$ & 3.261 & $\beta_{22}$ & 9.12 & 0.11 & $\beta_{22}+\beta_{62}$ & -1.48 & -0.024 \\
\hline$Y_{p}$ & $\beta_{32}$ & $7.80^{* * *}$ & 3.475 & $\beta_{32}$ & 7.8 & 0.93 & $\beta_{32}$ & 7.8 & 1.05 \\
\hline D3 & $\beta_{42}$ & $-148.34^{* *}$ & -2.545 & $\beta_{42}$ & -148.34 & & $\beta_{42}$ & -148 & \\
\hline$\left(P^{c *}\right) D P$ & $\beta_{52}$ & 3.22 & 0.622 & & & & & & \\
\hline$\left(W^{c *}\right) D P$ & $\beta_{62}$ & $-10.59^{* *}$ & -2.76 & & & & & & \\
\hline R-square $=$ & 0.891 & Adjusted R- & square $=($ & 357 & DW stllti & stic $=1.58$ & No. of obse & rvatic & $s=31$ \\
\hline
\end{tabular}

$D P=$ dummy for the structural adjustment period in Ghana; $D P= \begin{cases}1 & \text { if year }>1983 \\ 0 & \text { if year } \leq 1983\end{cases}$

${ }^{1}$ Elasticities were calculated by using the means in the respectIve periods.

*** Coefficients statistically significant at $1 \%$ level.

${ }^{* *}$ Coefficients statistically significant at $5 \%$ level.

*Coefficients statistically significant at $10 \%$ level.

producer price of cocoa, farmers may now have the incentive to rehabilitate existing farms. The use of insecticides becomes a significant factor in that effort and so is its price. Although all subsidies on inputs were removed in the post-adjustment period, because of expected increases in the producer price of cocoa, farmers found it relatively cheaper to rehabilitate existing farms by using insecticides rather than opening up new lands. Moreover, the increased availability of the input may have helped its more widespread use on cocoa farms

The $D 2$ variable represents a dummy for the period 1983-1986, a period when there was a drastic fall in cocoa land as a result of major bush fires in 1982/83. This variable is negative and significant (Table IV), confirming that bush fires had a significant effect on reduced cocoa land in the years immediately following the fires. Real per capita income $\left(Y_{p}\right)$ has a positive influence on cocoa land. A one per cent increase in real per capita income leads to $0.9 \%$ and $1.05 \%$ 
increase in harvested cocoa land in the pre and post-adjustment periods respectively (Table IV).

The above results provide no strong evidence that in Ghana increases in cocoa prices in the post-adjustment period may have led to increased forest loss through cocoa land expansion. However, higher prices of insecticides have rather helped to reduce the expansion in cocoa land. The tentative inference from these results is that the post-adjustment period policies, through both higher producer price of cocoa and the price (and the availability) of insecticides, may have made it possible for farmers to invest in existing lands rather than opening up new lands. The pressures on the forest land through cocoa land expansion in the adjustment period in Ghana should, therefore, be lower. The general conclusion from the cocoa land estimates for Ghana is that significant higher prices for cocoa and the availability of agricultural inputs, even where subsidies are removed, may help reduce the dependence of cocoa production on the forest land and reduce the rate of forest loss. These results, to a large extent, support the significant reduced role of cocoa land expansion in forest loss estimated equation in Table III.

\subsection{HARVESTED MAIZE LAND}

The Chow test on equation (10) confirmed a significant difference between the pre and post-adjustment period. However, the switching regression was preferred to the piecewise linear regression in estimating the structural shifts. Other price variables, $P^{c}, P^{h}, W^{c}, W^{h}$, and the real per capita GDP variable $\left(Y_{p}\right)$ were not significant and therefore were dropped. As expected, cocoa prices are not relevant because it is not easy to convert maize land to cocoa land. This requires a high capital investment to restore soil fertility depleted after maize farming. This investments in most cases could not be afforded by farmers in Ghana,

Moreover, the majority of trees which initially maybe needed to support cocoa cropping would have been cleared under maize farming. The insignificance of timber output and input prices was also expected, as the maize farmer has no influence on the allocation decisions of the forest for timber production in Ghana. The per capita GDP variable $\left(Y_{p}\right)$ also appear not to influence the demand for maize land.

The $D 2$ variable was included in the maize equation to test the hypothesis that, given the drastic fall in cocoa land in the 1983-1986 period, farmers may have diverted to food crop production such as maize. However, as this variable was not significant, this hypothesis of a substitutional shift from cocoa production into maize farming was rejected. The estimated maize land results are presented in Table V.

The variables that appear to influence the demand for maize land in Ghana are the population density (popd), the lagged price of maize $\left(P^{m}\right)$ and the price of fertilizer $\left(W^{m}\right)$. The price of maize is more important in the post-adjustment period while the price of fertilizer is important in both periods. 
Table V. Ordinary Least squares estimation of the maize land equation for Ghana Dependent variable $=L^{m}$ (harvested maize land in '000 ha)

Estimated switching regression for equation (10)

$$
\begin{aligned}
& \begin{array}{l}
L^{m}=\beta_{03}+ \\
\quad \\
\quad \\
\quad+\beta_{13} P_{t-1}^{m}\left(P_{t-1}^{m}\right) D S+\beta_{23} W^{m}+\beta_{33}\left(W^{m}\right) D S+\mu_{3 t}
\end{array} \\
& \text { where: } \\
& P_{t-1}^{m}=\text { real price of maize lagged one year } \\
& D S=\text { dummy for the structural adjustment period in Ghana; } D S= \begin{cases}1 & \text { if year } \geq 1983 \\
0 & \text { if year }<1983\end{cases}
\end{aligned}
$$

\begin{tabular}{|c|c|c|c|c|c|c|c|c|c|}
\hline \multirow{3}{*}{$\begin{array}{l}\text { Variables } \\
\text { Constant }\end{array}$} & \multicolumn{3}{|c|}{ Estimated results } & \multicolumn{3}{|c|}{ Pre-adjustment } & \multicolumn{3}{|c|}{ Post-adjustment } \\
\hline & \multicolumn{2}{|c|}{ coefficients } & t-values & \multicolumn{2}{|c|}{$\begin{array}{c}\text { marginal } \\
\text { values }\end{array}$} & \multirow[t]{2}{*}{$\begin{array}{l}\text { Est. } \\
\text { elast. }\end{array}$} & \multicolumn{2}{|c|}{$\begin{array}{c}\text { marginal } \\
\text { values }\end{array}$} & \multirow[t]{2}{*}{$\begin{array}{l}\text { Est. } \\
\text { elast. }\end{array}$} \\
\hline & $\beta_{03}$ & -338.5 & -1.34 & $\beta_{03}$ & -338.5 & & $\beta_{03}+\beta_{53}$ & -530.72 & \\
\hline$P_{t-1}^{m}$ & $\beta_{13}$ & -0.004 & -0.01 & $\beta_{13}$ & -0.004 & 0.0014 & $\beta_{13}+\beta_{63}$ & 1.899 & 0.337 \\
\hline$W^{m}$ & $\beta_{23}$ & $9.48^{*}$ & 2.05 & $\beta_{23}$ & 9.48 & 0.306 & $\beta_{23}+\beta_{73}$ & -0.095 & -0.004 \\
\hline popd & $\beta_{33}$ & $14.62^{* *}$ & 2.77 & $\beta_{33}$ & 14.62 & 1.75 & $\beta_{33}$ & 14.62 & 1.564 \\
\hline D2 & $\beta_{43}$ & 51.09 & 0.64 & $\beta_{43}$ & 51.09 & & $\beta_{43}$ & 51.09 & \\
\hline$D S$ & $\beta_{53}$ & -192.26 & -1.34 & & & & & & \\
\hline$\left(P_{t-1}^{m}\right) D S$ & $\beta_{63}$ & $1.90^{* *}$ & 2.75 & & & & & & \\
\hline$\left(W^{m}\right) D S$ & $\beta_{73}$ & $-9.57^{*}$ & -1.72 & & & & & & \\
\hline $\mathrm{R}$-square $=$ & 0.752 & Adjusted & $\mathrm{R}$-square & $=0.653$ & 3 DW sta & tistic $=$ & .768 No.o & f observati & ons $=30$ \\
\hline
\end{tabular}

*** Coefficient statistically significant at $1 \%$ level.

** Coefficient statistically significant at $5 \%$ level.

*Coefficient statistically significant at $10 \%$ level.

The price of maize was not a significant factor in the demand for maize land in the pre-adjustment era. This is not surprising, as during this period maize prices were administratively determined resulting in low and unstable prices in Ghana. As a consequence, maize farmers had little incentives to expand production (Benhin and Barbier 1999b). Moreover, the poor storage facilities and the government's inability to purchase all maize produce at the administrative determined prices meant that any excess supply of maize was a cost to the farmer, who had to dispose of them at relatively lower prices in the open market. Maize prices therefore became irrelevant consideration in determining the area of maize cropping.

In the post-adjustment period, the relationship between the lagged real price of maize variable and maize land in Ghana was positive and significant, indicating that a one per cent increase in the lagged price of maize led to a $0.34 \%$ increase in the demand for maize land in the current year (Table V). With the removal of the guaranteed or controlled prices under the adjustment programme, the price of maize became more market-determined, and thus a significant consideration in maize land decision making in this era in Ghana. As the price of maize increases in 
the previous year, farmers expect it to stay the same or even increase in the current year, they therefore modify their demand for all inputs, including maize land, in order to increase production.

The estimated results also show that the price of ammonium sulphate $\left(W^{m}\right)$ had a positive and significant influence on maize land in the pre-adjustment period in Ghana. A one per cent increase in the price of ammonium sulphate led to about $0.31 \%$ increase in the demand for maize land (Table V). This suggests that ammonium sulphate and maize land were substitute inputs in maize production. The inference is that, given the relative low and unstable prices of maize, maize farmers could not afford to purchase other farm inputs like fertilizer and therefore tended to substitute land or converted forest land for fertilizer in production.

In the post-adjustment period in Ghana, the impact of the price of ammonium sulphate on maize land was significantly negative, suggesting complementarity between these two inputs in maize production in Ghana (Table V). A one per cent increase in the price of ammonium sulphate leads to a $0.004 \%$ fall in the demand for maize land. The high dependence of maize farmers on land for production is therefore expected to fall. This result also suggests that in the post-adjustment period in Ghana, higher prices of fertilizer may also lead to a fall in the demand for maize land.

The population density variable (popd) had a positive impact on maize land expansion in the pre and post adjustment periods in Ghana (Table V). The results show that in the period 1965-1995, a one per cent increase in population density led to a $1.6 \%-1.8 \%$ increase in the demand for maize land in Ghana. These results reflect the importance of maize as a food crop in Ghana.

To summarize, in the pre-adjustment period in Ghana lower and unstable prices of maize and the unavailability of agricultural inputs, in spite of high subsidies may have led to increased maize land expansion. In the post-adjustment period, relative stable and rising maize prices may have also increased maize land expansion. On the other hand, the availability of inputs, in spite of the removal of subsidies, may have counteracted the pressures for maize land expansion. The results also show that, population may be a significant factor in the demand for maize land in Ghana.

\subsection{INDUSTRIAL ROUNDWOOD PRODUCTION}

The Chow test did not show any significant difference between the pre and post adjustment period regressors for equation (8). This was confirmed by the insignificance of the relevant dummy variables in both the piecewise linear and the switching regressions. Therefore, the linear regression without the adjustment coefficient dummy best describes industrial roundwood production in Ghana between 1965-1995. Other price variables (for cocoa and maize) were not significant in explaining timber production in Ghana. The coefficients of the real per capita GDP $\left(Y_{p}\right)$ and the population density ( $\left.p o p\right)$ were both negative but insignificant. Table VI 
Table VI. Ordinary Least squares estimation of the timber production equation for Ghana: Dependent variable $=H$ (total industrial roundwood in ' $000 \mathrm{cum})$

Estimated linear regression for equation (8):

\begin{tabular}{|c|c|c|c|c|}
\hline \multirow[t]{2}{*}{ Variables } & \multicolumn{4}{|c|}{ Estimated results $=$ Pre-adjustment $=$ Post-adjustment } \\
\hline & \multicolumn{2}{|c|}{ coefficients } & \multirow{2}{*}{$\begin{array}{c}\text { t-values } \\
1.52\end{array}$} & \multirow[t]{2}{*}{$\begin{array}{l}\text { Estimated } \\
\text { elasticities }\end{array}$} \\
\hline Constant & $\beta_{01}$ & 1893.43 & & \\
\hline$P^{h} / W^{h}$ & $\beta_{11}$ & $254.73^{* *}$ & 3.142 & 0.318 \\
\hline popd & $\beta_{12}$ & -8.943 & -0.719 & -0.295 \\
\hline$Y_{p}$ & $\beta_{13}$ & -3.34 & -0.536 & -0.338 \\
\hline R-square $=0.326$ & \multicolumn{2}{|c|}{ Adjusted R-square $=0.218$} & \multicolumn{2}{|c|}{ DW statistic $=1.81$} \\
\hline \multicolumn{3}{|c|}{ No. of observations $=31$} & & \\
\hline
\end{tabular}

\footnotetext{
*** Coefficient statistically significant at $1 \%$ level.

** Coefficient statistically significant at 5\% level.

${ }^{*}$ Coefficient statistically significant at $10 \%$ level.
}

shows that in Ghana, the relative output and input price of timber $\left(P^{h} / W^{h}\right)$ is the only significant variable influencing timber production over the period.

A one per cent increase in the relative price of timber leads to a $0.32 \%$ increase in timber production (Table VI). This result indicates that if timber extraction is inefficient, price increases which may lead to increased timber extraction may lead to increased forest loss in Ghana. To mitigate such effect, the cost of logging, in one way or the other must be increased. The inference from the timber results is that increases in timber price, due both to higher world market prices and the recent devaluation in the post-adjustment period, may lead to increasing deforestation in Ghana through stimulating timber production.

In summary, the analyses of this section indicate that increased crop price in the post-adjustment period may have led to greater demand for crop land. However, the removal of subsidies on agricultural inputs, the complementarity between agricultural inputs and land in crop production and the subsequent availability of inputs may have reduced crop land expansion. The combination of these changes together with other factors may help reduce the demand for converted forest land and therefore limit agricultural related forest loss, especially from cash crops like cocoa. For timber production, higher prices in the post-adjustment period may have increased timber production and timber-related deforestation. However, higher prices may not necessarily increase forest loss if they result in greater efficiency in timber extraction. Possible evidence of this effect is supported by the reduced role of timber extraction in forest loss equation in the post-adjustment era (see Table III).

In the final stages of the analysis, we estimate a biodiversity index for Ghana using equation (7) and Table I. The index together with the preceded regression 
results in Tables III-VI are employed to examine the impact of the adjustment programme on biodiversity loss in Ghana.

\subsection{BIODIVERSITY LOSS RESULTS}

The upper boundary species-area relationships in Table I are used to estimate biodiversity levels, $S$, in Ghana for the period 1965-1995, using the actual levels of closed forest area, $F$, harvested cocoa land, $L^{c}$ and harvested maize land, $L^{m}$ recorded over that period. ${ }^{10}$ The biodiversity estimates are used to make comparisons between the pre and the post-adjustment biodiversity levels.

To further investigate the impact of the adjustment on biodiversity, the estimates from the recursive model presented in Tables III-VI are used. The pre-adjustment estimates for forest land, cocoa land, maize land and timber production equations, are used to derive estimates for closed forest area, $\hat{F}_{1}$, harvested cocoa land, $\hat{L}_{1}^{c}$, and harvested maize land, $\hat{L}_{1}^{m}$ for the adjustment period. These estimates are in turn used to estimate biodiversity levels, $\hat{S}_{1}$ for the post-adjustment period. Comparison is then made between these derived estimated biodiversity levels, $\hat{S}_{1}$ and their corresponding actual levels, $S$, computed from the recorded forest land uses. The results are presented in Tables VII and VIII, and Figures 1 and 2.

The result indicates that biodiversity levels have fallen over the period, 19651995 (Table VII and Figure 1). This falling trend was however steeper in the pre-adjustment period than the post-adjustment period, suggesting that biodiversity loss was more rapid in the earlier period (Figure 1). The explanation is that, as shown earlier in the estimated recursive model, there is relatively more incentive to invest in existing lands, as in cocoa land, and use more insecticides and fertilizer as in cocoa land and maize land to increase production rather than rely on forest conversion. These incentives relate to higher prices for cocoa and maize, and the availability of inputs. Other incentives include high yielding variety seeds. The conclusion is that the SAP has provided a conducive environment for the less reliance on the forest for production and therefore the conservation of higher levels of biodiversity, or reduced rates of biodiversity loss.

The above outcome is confirmed in Table VIII and Figure 2. They show that if the pre-adjustment relationships in Tables III IV, V and VI, had continued in the post-adjustment period, the trend levels of biodiversity, $\hat{S}_{1}$, would have been lower than the actual levels in the post-adjustment period, $S$. In other words, biodiversity loss would have been higher than the actual estimates. The conclusion is that the Structural Adjustment may have helped reduce the rate of biodiversity loss in Ghana.

\section{Summary and Policy Implications}

This paper has used an empirical model to investigate the impacts on forest and biodiversity loss of the Structural Adjustment Programme (SAP) introduced in 
Table VII. Estimated biodiversity levels in Ghana, 1965-1995 $S=F^{(0.39)}+\left(L^{c}\right)^{(0.098)}+\left(L^{m}\right)^{(0.0195)}$

\begin{tabular}{|c|c|c|c|c|c|c|c|c|}
\hline & \multicolumn{4}{|c|}{ Pre-adjustment period } & \multicolumn{4}{|c|}{ Post-adjustment period } \\
\hline & 1965 & 1970 & 1975 & 1980 & 1983 & 1985 & 1990 & 1995 \\
\hline$F$ & 23278 & 21357 & 19432 & 18909 & 17504 & 17298 & 17086 & 16862 \\
\hline$L^{c}$ & 1830 & 1451 & 1400 & 1200 & 800 & 900 & 1050 & 1350 \\
\hline$L^{m}$ & 173 & 452 & 320 & 440 & 400 & 579 & 465 & 669 \\
\hline$S$ & 53.67 & 51.98 & 50.2 & 48.88 & 48.22 & 48.04 & 47.85 & 47.68 \\
\hline
\end{tabular}

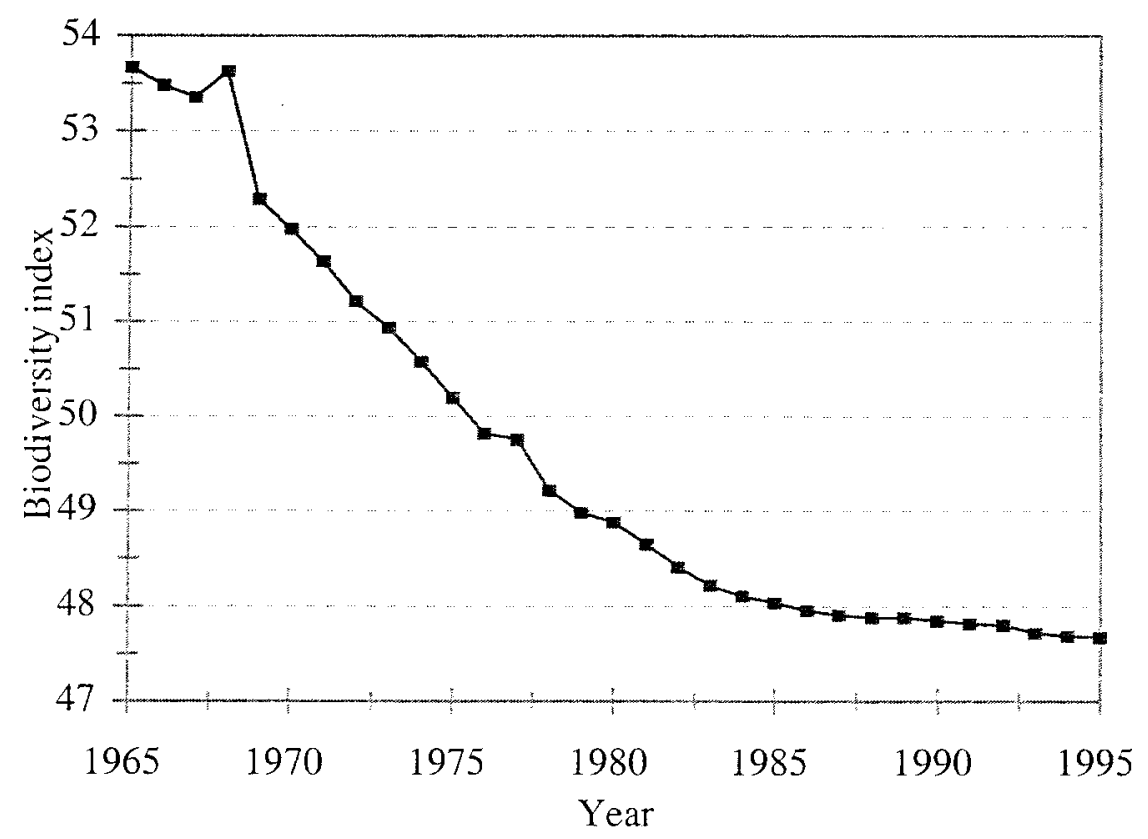

Figure 1. Estimated biodiversity levels in Ghana (1965-1995).

Ghana in 1983 directly through the proximate causes of agricultura1land expansion and timber production and indirectly through output and input prices for cocoa, maize and timber. Piecewise linear and switching regression approaches, which separated the pre from the post-adjustment period influences, were used to estimate a recursive model consisting of forest loss as well as cocoa land, maize land and timber production equations as a function of input and output prices. A specie-area relationship was employed to estimate a biodiversity index for Ghana in the pre and post-adjustment period. These estimates were used to investigate the influence of the structural adjustment programme on biodiversity loss. 
Table VIII. Estimated biodiversity levels in the post-adjustment period based on the imposed pre-adjustment relationship in Ghana

\begin{tabular}{lcrrr}
$\hat{S}_{1}=\hat{F}_{1}^{(0.39)}+\left(\hat{L}_{1}^{c}\right)^{(0.098)}+\left(\hat{L}_{1}^{m}\right)^{(0.0195)}$ \\
\hline \multicolumn{5}{c}{ Year } \\
\cline { 2 - 5 } & 1983 & 1985 & 1990 & 1995 \\
\hline$\hat{F}_{1}$ & 17349 & 17065 & 16809 & 16661 \\
$\hat{L}_{1}^{c}$ & 871 & 946 & 1090 & 961 \\
$\hat{L}_{1}^{m}$ & 469 & 602 & 927 & 996 \\
$\hat{S}_{1}$ & 48.08 & 47.81 & 47.59 & 47.41 \\
$S$ & 48.22 & 48.04 & 47.85 & 47.68 \\
\hline
\end{tabular}

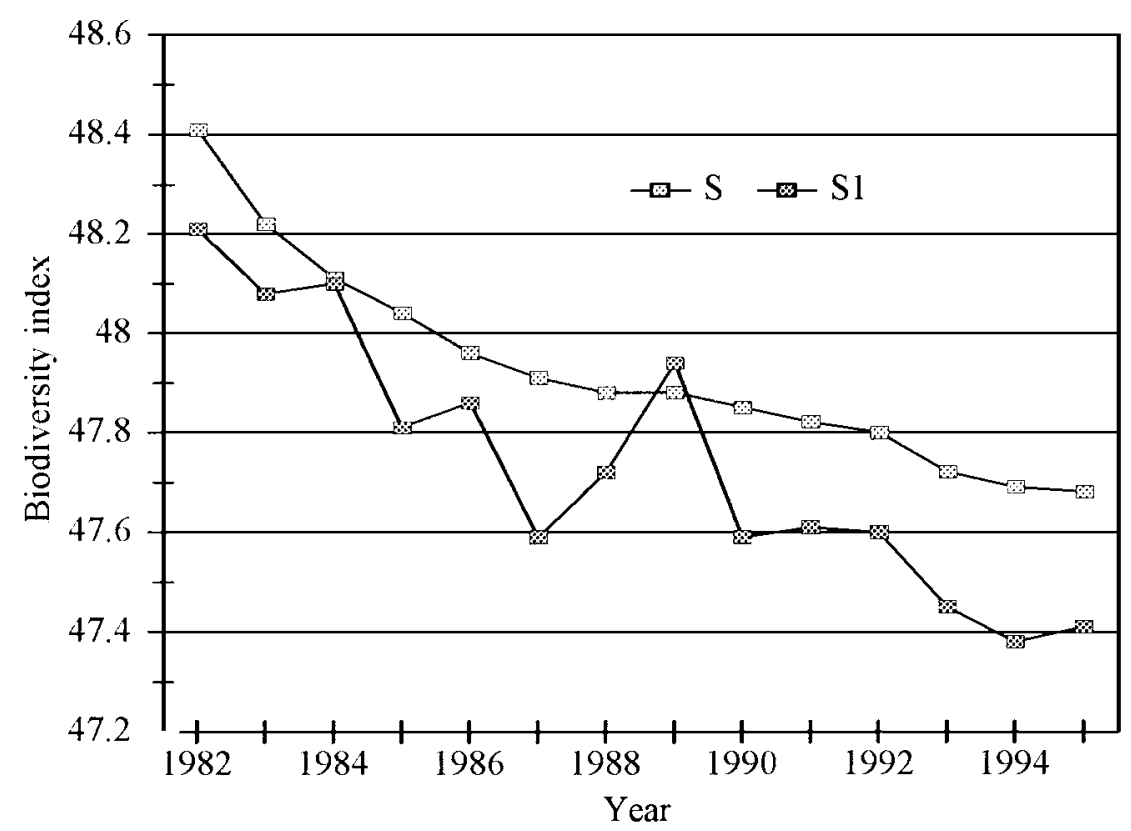

Where:

$\mathrm{S}=S=$ actual estimated biodiversity levels in the post-adjustment period (Table VII).

$\mathrm{S} 1=\hat{S}_{1}$, estimated biodiversity levels with the imposed pre-adjustment period relationships from Tables III, IV, V and VI (see Table VIII).

Figure 2. Biodiversity levels in the post-adjustment period in Ghana (1983-1995).

The results do not support the hypothesis that maize land expansion is a proximate cause of forest loss, either in the pre or the post adjustment period. Cocoa land expansion and timber extraction are significant factors, but their impacts on forest loss are reduced in the post-adjustment period. The inference is that the SAP has significantly reduced the impacts of cocoa land expansion and to a lesser extent 
timber extraction on forest loss. Expansion in cocoa land in the post-adjustment period, led to a reduced rate of forest loss as compared to the pre-adjustment period. This is attributable to some increased investment in existing cocoa land, probably as a result of an increased producer price for cocoa, the availability of needed inputs, and other efforts aimed at rehabilitating existing cocoa farms.

The biodiversity index estimates for Ghana also indicate that the rate of biodiversity loss has reduced in the post-adjustment period. In fact, if the preadjustment estimated relationships between the proximate and underlying causes of forest loss on one hand and biodiversity loss on the other, has existed in the postadjustment period, the rate of biodiversity would have been higher. The inference is that policies relating to prices and other incentives have reduced the rate of cocoa and maize land expansion, and improved timber extraction, may have helped reduce the rate of biodiversity loss.

In conclusion, we have demonstrated that the cocoa and maize policies undertaken under the Structural Adjustment Programme since 1983 have influenced the demand for maize and cocoa land and thus forest land. Although we found little significant impact of the SAP on timber harvesting trends, we found that the relative returns to timber production have an important impact on the rate of deforestation in Ghana. More important, SAP policies such as the removal of subsidies on agricultural inputs together with higher crop prices appear to reduce the reliance of crop production such as cocoa on the forest and therefore reduce cocoa-related deforestation. Given the relationship between forest area loss and biodiversity loss, the SAP may have also helped reduce the rate of biodiversity loss.

The main policy implication is that, getting prices "right" may help reduce forest and biodiversity loss in Ghana, though the availability of alternative sources of production (inputs) is also very important. Rules and regulations are important in controlling forest loss, but as has been shown, in spite of the rules and regulations existing in the pre-adjustment period, the rate of forest loss was still high. This may be attributable to the less "right" prices which were not an incentive for investment in existing cocoa and maize lands, and efficient timber production. In the postadjustment period, similar rules and regulations are in place, however, with the right signals from prices, farmers are increasingly investing in existing lands rather than relying predominantly on forest land. Timber extractors are also being more efficient. These, to a large extent may be the cause of the falling rate of forest and biodiversity loss in Ghana in the post-adjustment period.

\section{Notes}

1. Biodiversity, according to Article two of the Convention on Biological Diversity, is the variability among living organisms from all sources including inter alia, marine and other aquatic ecosystems and the ecological complexes of which they are part. This includes diversity within species, between species and of the ecosystem (Glowka 1994). The Global Biodiversity Assessment (UNEP 1995) also defines biodiversity as the total diversity and variability among living things and of the systems of which they are part, which covers the total range of variation in and 
variability among systems and organisms, at the regional, landscape, ecosystem and habitat level, at the various organism levels down to species, population and genes and the complex sets of structural and functional relationships within and between these different levels of organizations, including human action, and their origins and evolution in space.

2. See for example, Connor and McCoy (1979) and Simberloff (1986).

3. This is based on the fact that cocoa can successfully grow on land which support heavy type of tropical rain forest (Manu and Tetteh 1987). These forests consist of patches of permanent forests, temporary forest (both of which provide shades) and mangroves. Maize land may also contain some mangroves.

4. This follows similar studies such as; Barbier and Burgess (1997); Capistrano (1994); Cropper and Griffiths (1994); Margulis (1991) and Southgate et al. (1991). It can be argued that real exchange rates and technological change are also important variables that need to be examined under analysis of the impact of the SAP. This is true for real exchange rate, given that an important aspect of the SAP in Ghana is devaluation. However, it must be noted that the rate of devaluation is reflected in input prices. It is also reflected in the producer prices for cocoa. Including the variable in the model will introduce a high level of multicollinearity in the explanatory variables with their associated econometric problems (see Gujarati 1995, pp. 319-353). Technology change was introduced in the model as a dummy; $0=$ pre-adjustment period and 1 = post-adjustment period, but the estimated coefficient was not significant and the estimated model did not improve in any significant way.

5. The piecewise linear regression assumes that the true model being estimated is continuous, with a structural break. The switching regression also assumes that the model has a structural break, but the regression relationship is not continuous (see Pindyck and Rubinfeld 1991, pp. 117-120). In addition, the Hausman specification error test was used to test for the simultaneity/exogeneity of the per capita GDP $\left(Y_{p}\right)$ in the estimated harvested cocoa land equation (see Table IV) and the timber production equation (see Table VI) (see Gujarati 1995, pp. 669-673). The test showed that per capita GDP $\left(Y_{p}\right)$ is exogenous and there is no simultaneity bias in our system of equations. This further substantiated the recursivity of the model and the use of the OLS for estimating each equation.

6. There are a1ot of arguments against the use of FAO data for such analysis (see Kaimowitz and Angelsen 1997). This unreliability should be considered in interpreting the results. The use of forestry data from the FAO for deforestation analysis has been criticised because of its reliance on population density in its indirect estimation methodology. In recent times, however, remote sensing approach have been used to give a more accurate estimate (Rudel and Roper 1997). However, Ghana is among the countries that is yet to fully use this new estimation approach. The FAO data at present is the only reliable time series for such analysis. Moreover, given the poor nature of historical price data and area cultivated data in developing countries, such as Ghana, caution should be taken in interpreting the results of our analysis, though it provides a good reflection of the impact of the structural adjustment programme on forest and biodiverrsity loss in Ghana.

7. The model is recursive because it displays a zero contemporaneous correlation between the disturbance terms and the matrix of the coefficients of the endogenous variables is triangular (see Gujarati 1995, pp. 680-682).

8. The nature of the forest loss equation itself (the first differencing of some of the variables in the equation) removed the presence of autocorrelation.

9. The change in maize land $\left(L_{t}^{m}-L_{t-1}^{m}\right)$ variable was dropped from the estimated forest loss equation because it was not statistically significant and its inclusion did not also improve upon the significance of the whole model. $D 1$ was included in the equation as a dummy to capture the increase in total forest area in 1968, due to the re-demarcation of more forest lands as reserve forests in Ghana. The dummy variable is negative and very significant as expected, indicating 
that the re-demarcation of new forest reserves led to increased total closed forest area and helped reduce the total amount of forest loss.

10. The lower boundary estimates will follow similar trends as the upper boundary. Since the interest of this study is more in the trend changes, the choice of either of the boundaries will not make much difference.

\section{References}

Abbiw, D. K. (1989), 'Non-wood Forest Products (minor forest products)', Ghana Forest Inventory Project Seminar Proceedings, 79-88. Accra: Ghana Forestry Department.

Alexandre, D. Y. (1978), 'Le rôle Disseminateur des éléphants en forêt de Taï, Côte d'Ivoire', La Terre et la Vie 32, 47-72.

Amelung, T. and M. Diehl (1992), 'Deforestation of Tropical Rainforests: Economic Causes and Impact on Development'. Kieler Studien 241. Tubingen: J.C.B. Mohr.

Barbier, E. B. (1994), 'The Environmental Effect of the Forestry Sector', in The Environmental Effects of Trade. Paris: Organization of Economic Cooperation and Development (OECD).

Barbier, E. B. and J. C. Burgess (1997), 'The Economics of Tropical Forest Land Use Options', Land Economics 73(2), 174-195.

Barbier, E. B., J. C. Burgess and C. Folke (1995), Paradise Lost? The Ecological Economics of Biodiversity. London: Earthscan.

Bateman, M. J. et al. (1989), An Analytical Review of Ghana's Cocoa Pricing Policy with Recommendation for Future Policy Formulation, A Report Prepared for the World Bank. Washington, DC: World Bank.

Benhin, J. K. A. and E. B. Barbier (2001), 'The Effects of the Structural Adjustment Program on Deforestation in Ghana'. Agricultural and Resource Economics Review (forthcoming).

Benhin, J. K. A. and E. B. Barbier (1999a), Structural Adjustment Programme, Deforestation and Biodiversity Loss in Ghana, A Paper Presented at the Ninth Annual Congress of the European Association of Environmental and Resource Economists (EAERE), Oslo, 25-27 June.

Benhin, J. K. A. and E. B. Barbier (1999b), A Comparative Analysis of the Effects of Structural Adjustment on Agriculture and on Forest Cover in Cameroon and in Ghana, Final Report Prepared for the Center for International Forestry Research (CIFOR), Bogor, unpublished.

Brown, K. and D. Pearce, eds. (1994), The Causes of Tropical Deforestation. London: University College London Press.

Burgess, P. F. (1971), 'The Effects of Logging on Hill Depterocarp Forest', Malaysia Nature Journal 24, 231-237.

Capistrano, A. D. (1994), 'Tropical Forest Depletion and the Changing Macroeconomy, 1967-1985', in K. Brown and D. W. Pearce, eds., The Causes of Tropical Deforestation (pp. 68-85). London: University College London Press.

Chachu, R. (1989), 'Allowable Cut from the Forest', in J. Wong, ed., Ghana Forest Inventory Project Seminar Proceedings 29-30 March 1989. Accra: Ghana Forestry Department and ODA.

Connor, E. F. and E. D. McCoy (1979), 'The Statistics and Biology of Species-area Relationship', American Naturalist 13, 791-833.

Cropper, M. and C. Griffiths (1994), 'The Interaction of Population Growth and Environmental Quality', American Economic Review 84(2), 250-254.

Deacon, R. T. (1995), 'Assessing the Relationship between Government Policy and Deforestation', Journal of Environmental Economics and Management 28, 1-8.

Ehui, S. K. and T. W. Hertel (1989). 'Deforestation and Agricultural roductivity in the Côte d'Ivoire', American Journal of Agricultural Economics 71(3), 703-711.

FAO (1999), FAOSTATS Database, CD-ROM. Rome: FAO.

FAO (1997), State of the World's Forests 1997. Rome: FAO. 
Friends of the Earth (1992), Plunder of Ghana's Rainforest for Illegal Profit, Vol. 2: Research Report. London: Friends of the Earth.

Gartlan, S. (1990), Practical Constraints on Sustainable Logging in Cameroon, Paper Presented at the Abidjan Conference on Forest Conservation in West and Central Africa, November.

Glowka, L., F. Burhenne-Guilmin, H. Synge, J. McNeely and L. Gündling (1994), 'A Guide to the Convention on Biological Diversity', Environmental and Policy Paper No. 30. IUCN.

Gujarati, D. N. (1995), Basic Econometrics, 3rd ed. New York: McGraw-Hill, Inc.

Hawthorne, W. D. (1989), 'The Flora and Vegetation of Ghana's Forests', in Ghana Forestry Inventory Project Seminar Proceedings, 8-14. Accra: Forestry Department.

ICBP/IUCN (1985), Threatened Birds of Africa and Related Islands: The ICBP/IUCN Red Data Book, Part 1. Cambridge: ICBP/IUCN.

ISSER (1992), The State of the Ghanaian Economy in 1991. Accra: ISSER, University of Ghana.

ISSER (1996), The State of the Ghanaian Economy in 1995. Accra: ISSER, University of Ghana.

ITTO (1993), Study of Incentives for the Sustainable Management of the Tropical High Forest of Ghana, A Report Prepared by IIED and the Forestry Department Of Ghana, unpublished.

IUCN (1988), Ghana, Conservation of Biological Diversity. Briefing Paper Prepared by the International Union for the Conservation of Nature and Natural Resources, Tropical Forest Programme, Cambridge.

Kaimowitz, D. and A. Angelsen (1997), A Users Guide to Economic Models of Deforestation. Bogor: Center for International Forestry Research (CIFOR).

Kingdon, J. (1990), Island Africa: The Evolution of Africa's Rare Animals and Plants. London: Collins.

López, R. (1997), 'Environmental Externalities in Traditional Agriculture and the Impact of Trade Liberalization: The Case of Ghana', Journal of Development Economics 53, 17-39.

Lugo, A. E., J. A. Parrotta and S. Brown (1993), 'Loss of Species Caused by Tropical Deforestation and their Recovery through Management', AMBIO 22(2-3), 106-109.

Manu, M. and E. K. Tetteh (1987), A Guide to Cocoa Cultivation. Accra: Cocoa Research Institute of Ghana, Ghana Cocoa Board.

Martin, C. (1991), The Rainforests of West Africa: Ecology. Accra: Elsevier Publishers.

Mensah-Ntiamoa, A. Y. (1989), Pre-feasibility Study of Wildlife Potentials in the Kakum and AsinAttandoso Forest Feserves - Central Region - Ghana. Accra: Department of Game and Wildlife, unpublished.

Ministry of Agriculture (1991), Agriculture in Ghana: Facts and Figures. Accra: Policy Planning, Monitoring and Evaluation Department (PPMED), Ministry of Agriculture.

Munasinghe, M. (1999), 'Introduction: Special Topic 1 - Structural Adjustment Policies and the Environment', Environment and Development Economics 4, 9-18.

Munasinghe, M. (1996), 'An Overview of the Environmental Impacts of Macroeconomic and Sectoral Policies', in M. Munasinghe, ed., Environmental Impacts of Macroeconomic and Sectoral Policies (pp. 1-14). Washington, DC: World Bank.

Myers, N. (1989), Deforestation Rates in Tropical Forests and their Climatic Implications. London: Friends of the Earth.

Oldfield, S. (1991), Pre-project Study on the Conservation Status of Tropical Timbers in Trade. Final Report Prepared for the International Tropical Timber Organization by the World Conservation Monitoring Centre, February 1991, Cambridge.

Olsen, D. K. and S. Curtin (1984), 'The Role of Economic Timber Specie in the Ecology of Black and White Colobus and Dana Monkeys in Bia National Park, Ghana', International Journal of Primatology.

Perrings, C. (2000), 'The Biodiversity Convention and Biodiversity Loss in Sub-Saharan Africa', in C. Perrings, ed., The Economics of Biodiversity Conservation in Sub-Saharan Africa: Mending the Ark. Cheltenham: Edward Elgar. 
Pindyck, R. S. and D. L. Rubinfeld (1991), Econometric Models and Economic Forecasts. New York: McGraw-Hill, Inc.

Reed, D. (1996), Structural Adjustment, the Environment, and Sustainable Development. London: Earthscan.

Reid, W. V. (1992), 'How Many Species Will There Be?', in T. C. Whitmore and J. A. Sayer, eds., Tropical Deforestation and Species Extinction. London: Chapman and Hall.

Repetto, R. (1988), The Forests for the Trees? Government Policies and the Misuse of Forest Resources. Washington, DC: World Resources Institute (WRI).

Richards, M. (1995), Role of Demand Side Incentives in Fine Grained Protection: A Case Study of Ghana's Tropical High Forests. London: ODA.

Rudel, T. and J. Roper (1997), 'The Paths to Rain Forest Destruction: Crossnational Patterns of Tropical Deforestation, 1975-1990'. World Development 25(1), 53-65.

Sankhayan, P. L. (1996), 'Effects of Structural Adjustment Programmes on Cropping Pattern and Environment: A Study in the Southern Highlands of Tanzania', in Structural Adjustment Policies and Environmental Degradation in Tanzania, Zambia and Ethiopia, Preliminary Seminar Report, 9-10 January. Agricultural University of Norway.

Sayer, J. A., C. S. Harcourt and N. M. Collins (1992), The Conservation Atlas of Tropical Forests: Africa. London: Macmillan Pub.

Simberloff, D. (1986), 'Are We on a Verge of a Mass Extinction in Tropical Rain Forests?', in D. K. Elliot, ed., Dynamics of Extinction. New York: John Wiley.

Southgate, D., R. Sierra and L. Brown (1991), 'The Causes of Tropical Deforestation in Ecuador, A Statistical Analysis', World Development 19(9), 1145-1151.

Struhsaker, T. T. and J. F. Oates (1975), 'Comparison of the Behaviour and Ecology of Red Colobus and the Black and White Colobus Monkeys in Uganda', in Socio-ecology and Psychology of Primates. The Hague.

Sun, C. (1995), Tropical Deforestation and the Economics of Timber Concession Design. Department of Agricultural Economics, University of Illinois at Urbana-Champaign, Urbana, Doctoral Dissertation Proposal.

UNEP (1995), Global Biodiversity Assessment. London: Cambridge University Press.

Wong, J. (1989), Ghana Forest Inventory Project Seminar Proceedings, 29-30 March 1989. Accra: Ghana Forestry Department and the ODA.

World Bank (1989), World Development Report 1989. Oxford: Oxford University Press.

World Conservation Monitoring Centre (WCMC) (1992), Global Biodiversity: Status of the Earth's Living Resources. London: Chapman and Hall.

World Resources Institute (WRI) (1994), World Resources 1994-1995: People and the Environment. Oxford: Oxford University Press.

\section{Appendix 1: Data construction for the analysis}

\section{Forest land}

Forest area is defined as the total closed forest area in Sq. $\mathrm{km}$ in Ghana in a given year. It is generally the summation of the reserved and unreserved closed fores area. The negative of the first difference in total closed area represents the change in forest area. Closed forest area is used because it contains the major extractable economic timber species, and it also provides the best soil nutrients for cocoa and maize. Data for the 1965-1991 from the Forestry Department of Ghana and the FAO. Extrapolation technique is used is to estimate for the 1992-1995 period. This is done by using the FAO estimate of an average rate of change of $-1.3 \%$ in forest in Ghana between 1991-1995 (FAO 1997). An alternative 
extrapolation method is the use of an estimated model of forest area-time relationship with the available data which is then used to estimated for the missing values. This latter method was used by Ehui and Hertel (1989). They estimated a forest area-time relationship, $F(t)=22.83944 e^{-0.0493 * t}$, where $t$ is the number of years, to estimate their missing forest data. Included, in their estimation, however, were the values of the initial forest stock and the end period forest stock. In our study, the end period forest stock data was not available, the reason for the method we chose. It could be argued that this method does not provide an appropriate estimate for the missing data, however, it is the best estimation procedure given the available data and information.

\section{Cocoa land}

Harvested cocoa land is used as a proxy for harvested cocoa land. This follows most studies on land use analysis. Change in cocoa land was estimated as the first difference in total harvested cocoa land in each year.

\section{Maize land}

Harvested maize land is also used a proxy maize land, with the first difference also representing the change in maize land.

\section{Timber production}

Total industrial round wood production is also used as a proxy for total timber production. This also follows many studies done in this area. This variable has no counterpart of a change variable as in cocoa and maize land, since there are no additions to its level, which is per given year.

\section{Output prices}

The consumer price index in 1990 values was used to change nominal prices into real values. This method was adopted following Amin (1995) and other studies. The nominal prices used were the producer price in Ghanaian Cedis per ton of cocoa as provided by the Cocobod, Accra, and ISSER (1996). Guaranteed minimum price and market prices of $100 \mathrm{~kg}$ of maize were provided by the Policy Planning, Monitoring and Evaluation Department (PPMED) of the Ministry of Agriculture in Ghana. The average export priced of industrial in Cedis per cubic metre calculated from the Timber Export Development Board (TEDB) in Ghana, using exchange rates provided by the IMF's International Financial Statistics (IFS) Yearbooks.

\section{Input prices}

The sources of the price of insecticides and ammonium sulphate which were used as proxies for input used in cocoa and maize production respectively were taken from Stryker, D.J. et al. (1990) and ISSER $(1993,1996)$. The sum of logging costs provided by the TEDB were used as a proxy for input prices for timber production. 